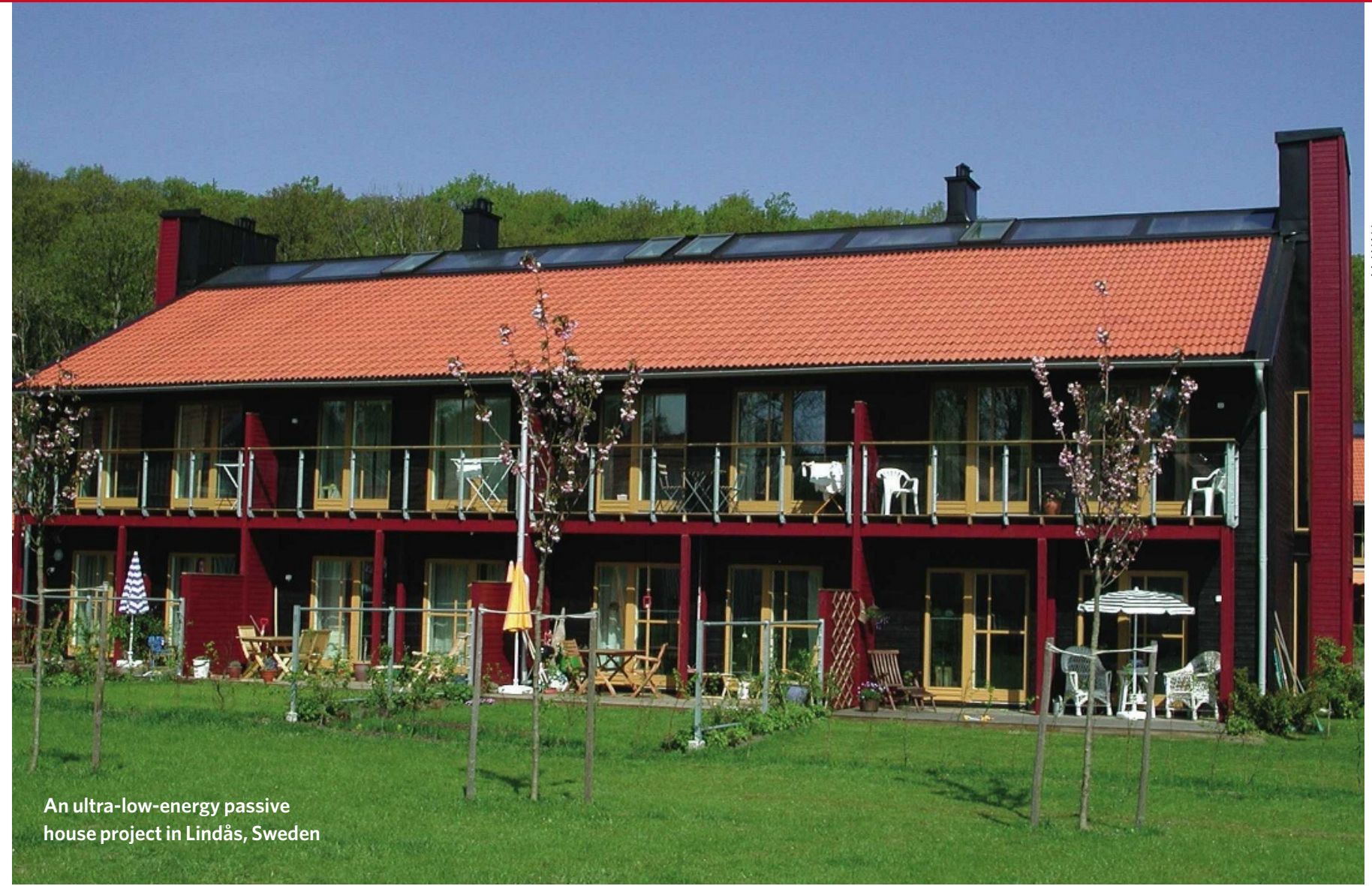

\title{
Architects of a low-energy future
}

Low- and zero-energy buildings could have a huge impact on energy use and carbon emissions. We have the technologies, but if they are to mitigate climate change, green-building design must hit the mass market, says Declan Butler.

| / t felt surreal," says Karsten Voss, thinking back to January 2008 and the winter meeting of the 50,000-member international heating, cooling and ventilation research association, ASHRAE. "Here we were sitting talking about zero-energy buildings, one of the biggest topics on the programme, inside a hotel that had no proper glazing or insulation - while it was $-10^{\circ} \mathrm{C}$ outside."

It was a classic illustration of both the challenge and the promise of green architecture, says Voss, who should know. An architectural engineer at the University of Wuppertal in Germany, he also heads assessment of ultralow-energy building demonstration projects built under the country's national programme on research for energy-optimized construction (EnOB). Germany has pioneered such research, thanks to its long-standing interest in the environment, and has some of the toughest energy-efficiency regulations around.

Buildings worldwide account for as much as $45 \%$ of energy consumption, and a similar share of greenhouse-gas emissions. That makes buildings the biggest single contributor to anthropogenic climate change - a worse offender than all the world's cars and trucks put together. But it also makes the design of energy-efficient buildings a "monumental but essential task" in the effort to mitigate climate change, according to a research roadmap published last November by the research committee of the US Green Building Council. Indeed, the latest report from the Intergovernmental Panel on Climate Change (IPCC) estimates that improvements in the energy efficiency of buildings could potentially reduce projected global carbon emissions up to $29 \%$ by 2020 , and up to $40 \%$ by 2030 . Moreover, the IPCC's estimates are deliberately conservative, based on a pessimistic view of how rapidly the building industry can reform its practices. If the reforms could somehow be accelerated, the reductions in fossil-fuel energy needs could be that much more dramatic.

Such a speed-up is certainly possible - in principle. Voss and his fellow 'green-building researchers' have already developed and tested many of the necessary tools and strategies, to the point where they can now build homes, offices and other buildings that use $80-90 \%$ less energy than existing buildings. The most efficient of these structures are almost completely 'passive', meaning they require very little, if any, traditional heating or air-conditioning. Yet the overall comfort they provide is, if anything, superior to existing buildings. Nor is there necessarily a cost penalty: these ultra-energy-efficient buildings are often no more expensive to build than conventional structures, and work out far cheaper if energy bills during their occupation are taken into account.

In practice, however, getting the construction industry to change its ways is a daunting prospect. Especially in the developed world, more than a century of cheap energy has divorced the architecture of buildings from energy considerations, and from their environment. Architects typically design whatever their client wants, mostly on the basis of cost or aesthetics, and then pass the design to engineers who have to make the building work and be comfortable - typically by bolting on energy-intensive air-conditioning, heating, artificial lighting and whatever else it takes. As a result, most builders and architects 
today haven't got a clue how to design buildings with ultra-low carbon emissions.

And even if they did, there is the sheer scale and diversity of the trillion-dollar worldwide building industry - a vast labyrinth that involves as many different professions and sectors as there are sorts of wallpaper, plus an almost unlimited number of types of buildings, regulations, norms, materials and environments. In the face of all that, "the major impediments to increase energy efficiency in the building sector are institutional barriers and market failures rather than technical problems," notes a report on green buildings published last year by the United Nations Environmental Programme. "Even if hightech competence exists in most countries, the institutional and economic conditions have hindered the technical competence to be effectively applied in day-to-day design, construction and operation of buildings."

Change is in the air, however. Green buildings, once the preserve of ardent environmentalists, are going mainstream. Architect Edward Mazria of Architecture 2030, a non-profit organization in Santa Fe, New Mexico, set a challenge in 2006 - a voluntary commitment to reduce the carbon consumption of all new and retrofitted buildings by $50 \%$ immediately, and to meet further reduction milestones to become carbon
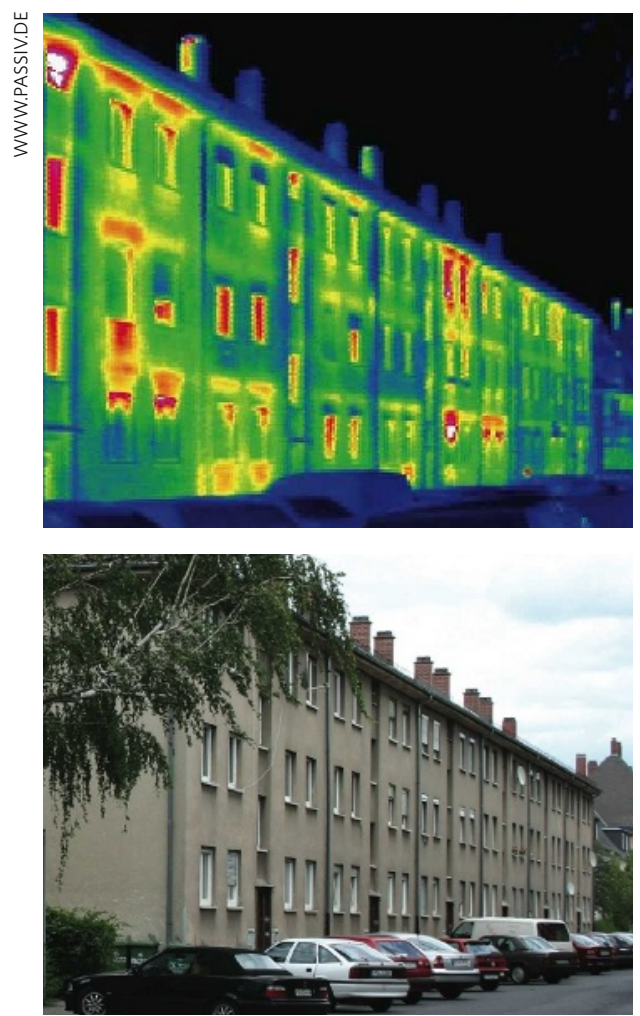

A 1950s building in Frankfurt, Germany before (left) and after (right) refurbishment. Thermograms (top) show the reduction in heat loss - energy demand dropped $90 \%$.

One driver is growing public concern over spiralling fuel prices and climate change, says Ken Baker, chief economist of the American Institute of Architects. The institute surveyed house purchasers' expectations at the end of 2007 and found that, despite the subprime
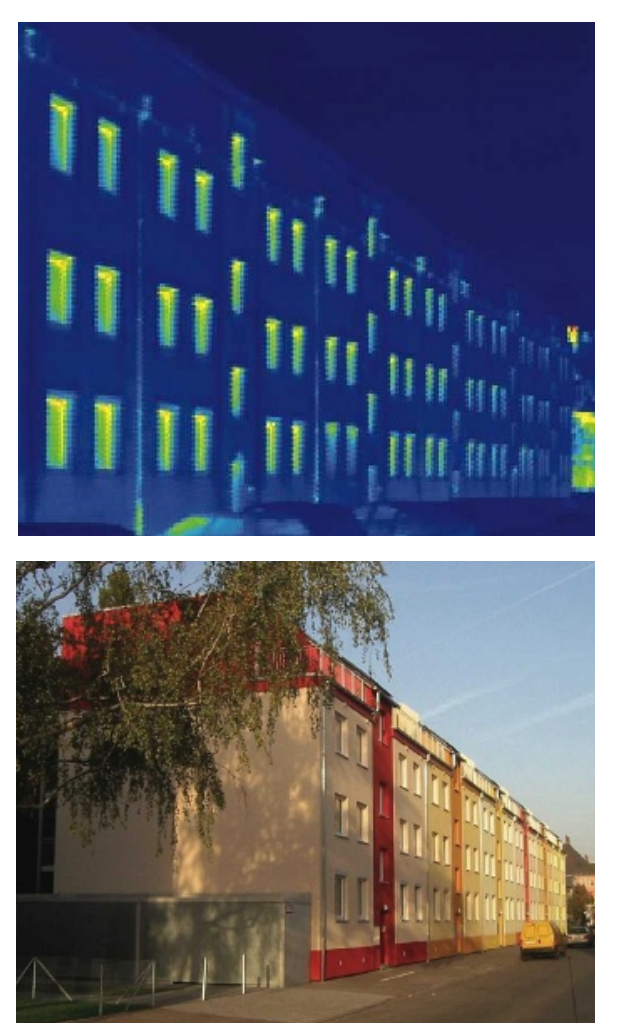
tects and more than 400 other professional organizations.

Meanwhile, the US Energy Independence and Security Act, which came into force in December last year, requires all federal buildings to meet stepwise goals almost identical

"Consumers are
increasingly aware
of energy-efficient
options."
- Ken Baker

mortgage crisis, most were willing to pay more for a house that would use less energy and be kinder on the planet. "Consumers are becoming increasingly aware of energy-efficient options," says Baker, "and they are requesting that architects to those of Architecture 2030's challenge. The act also introduces tougher energy targets for both commercial and residential buildings. In Europe and elsewhere, similar, or even tougher, targets are often being made legally binding on many buildings.

There is a "sea change" underway, says Gregor Henze, an architectural engineer at the University of Nebraska-Lincoln in Omaha. Carbon emissions weren't even on the radar of most architects five years ago, he says, adding that the number of architect firms, construction companies and other members of the US Green Building Council is "exploding" - it now has 13,500 member organizations, and 91,000 members, up some ten-fold since 2000 . incorporate them into the design and remodelling of their homes."

\section{Innovate and renovate}

Meanwhile, green-building researchers are working hard to expand those options. The most obvious and urgent priority is to take energy into account during retrofitting. Although new construction in Europe and the United States annually amounts to around $1 \%$ of the existing building stock, about twice that many structures are renovated every year. Given the typical life cycle of buildings, each renovation that uses inadequate insulation or poorly glazed windows is an opportunity for lowering energy demand that is lost for decades. One demonstration project carried out at the Jülich Research Centre in Germany shows what can be done with energy-efficient design strategies. Although the gains are not as impressive as those with new buildings, the renovations nonetheless cut the test building's total primary energy needs in half, from 1,235 kilowatt hours per square metre per year $\left(\mathrm{kWh} / \mathrm{m}^{2} /\right.$ year) to $600 \mathrm{kWh} / \mathrm{m}^{2} /$ year.

Ultimately, however, the biggest pay-offs will come from new buildings, where ultralow-energy use can be designed in from the beginning. This is particularly important for the developing world, and urban areas, where so much new construction is expected in coming decades. The goal in such ultra-low-energy design is to make buildings as 'passive' as possible, meaning they can satisfy most of their occupants' heating, cooling, and lighting needs from the outside environment - and then maintain the occupants' comfort as the outside cycles from day to night, summer to winter.

More research is still needed, for example, to develop cheap glazing and insulation materials that can adapt themselves to changes in lighting and heating loads over the course of a day, or a season. Research is also vital to adapt existing solutions to different sorts of buildings or environments.

Nonetheless, many of the technologies are already mature. Almost two decades of 
research, mainly in Europe, has resulted in designs for fully passive houses that require primary energy needs of $15-50 \mathrm{kWh} / \mathrm{m}^{2} /$ year - compared with current-generation European houses that typically require 160-300 $\mathrm{kWh} / \mathrm{m}^{2} /$ year - and need only supplementary heating or cooling, in tiny amounts, or just on the coldest and hottest days.

Such efficiency levels make the buildings amenable to being made zero-carbon by meeting their low energy needs, either from small, local renewable sources, or using grid electricity generated from renewable sources.

"You can do a lot with existing technology", says George Jeronimidis, an engineer who heads the Centre for Biomimetics at the University of Reading, UK, and who is developing next-generation building materials that adapt their shape, such as vents that open and close in response to humidity levels. "We are missing a lot of opportunities because we don't think about energy in the design phase of a building."

\section{Holistic house-building}

This does require a different mindset, says Maria Wall, a green-building researcher at the University of Lund in Sweden who was involved in building passive terrace houses in Lindås (see photo, page 520). "Getting architects and engineers sitting down together from the outset is critical," she says. "One has to consider the building as a whole, and in the context of its environment." But new software is helping architects and engineers do just that, says Andreas Wagner, a building scientist who heads the architecture faculty at the University of Karlsruhe in Germany, and who is also a member of the design and monitoring team within the EnOB programme.

The software provides a "common language" that allows architects and engineers to jointly quantify the energy implications of design decisions. Using databases and models of average temperatures, sunlight and solar radiation from different north-south orientations, it allows them to pick from a supermarket of passive design strategies, techniques and materials to adapt designs to the local conditions. "We

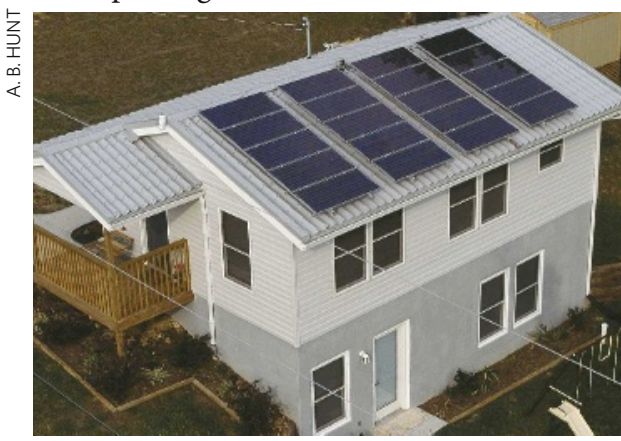

Energy-efficient homes in Lenoir City, Tennessee (left), and in Oberdorf, Switzerland.

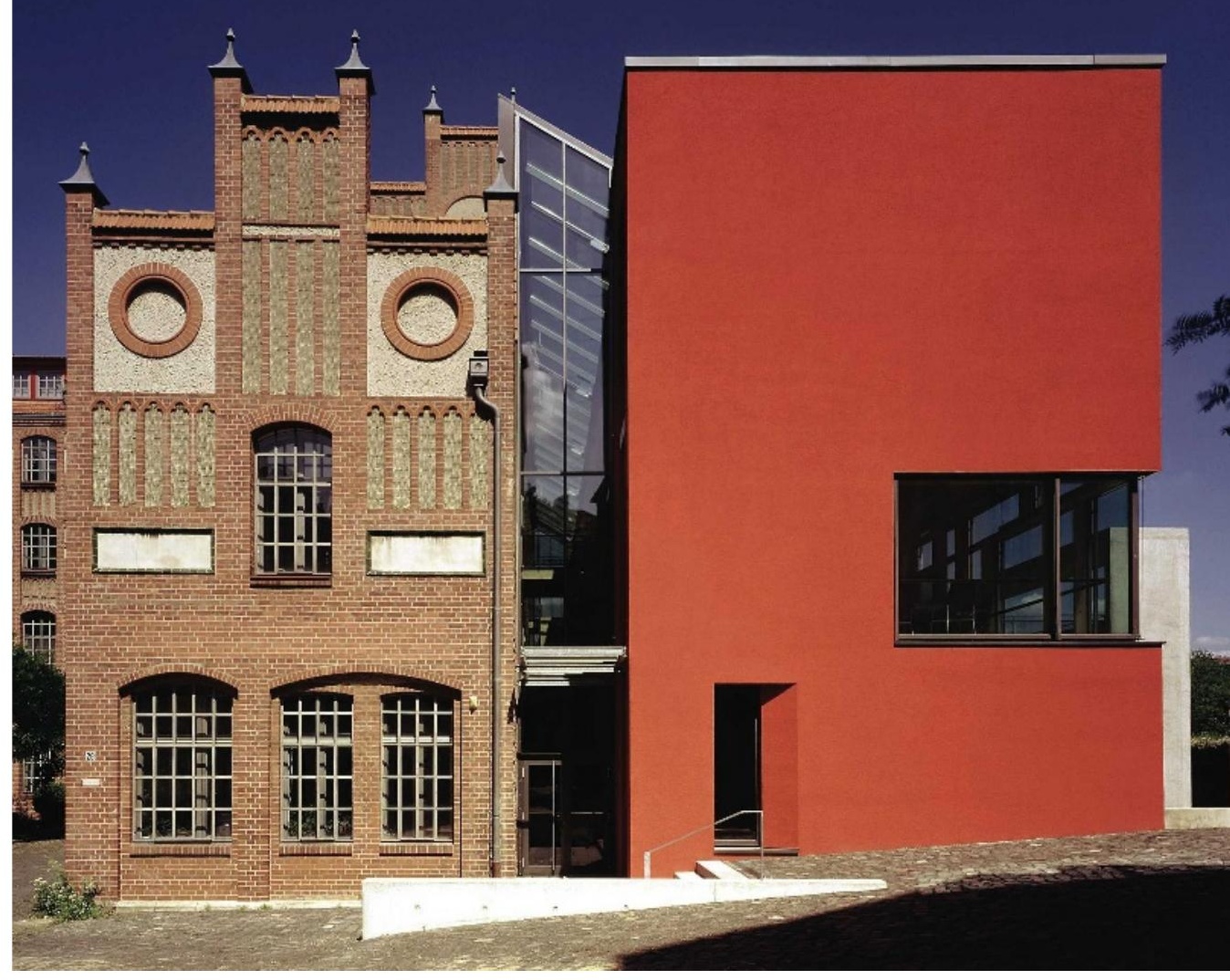

The Centre for Environmentally Conscious Construction in Kassel, Germany, leads by example.

are now moving on from research and prototypes into the building market," says Wagner.

That market is most mature for residential homes, which account for three-quarters of the energy consumption of the building sector. Passive houses currently make up only $2 \%$ of new buildings in Germany. But market research suggests that fraction will climb quickly as the necessary competences spread, and as consumers begin to take advantage of low-interest loans and other recent government incentives. Passive houses are also spreading fast in Austria, Switzerland and other European countries.

Passive-house design uses extreme insulation of the building envelope - including triple-glazed windows, often filled with an inert gas - in particular, in an effort to eliminate what engineers call 'thermal bridges'. These are fault lines, typically at the window frames and at the intersection of floors and walls, where large, unwanted energy transfers occur with the outside. The result is an airtight 'skin' that

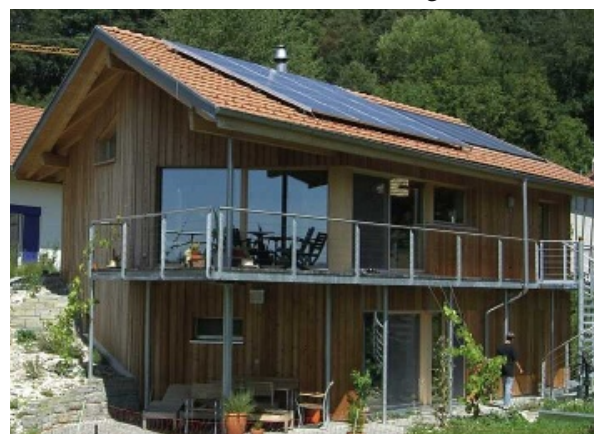

prevents energy leakage. Thermograms of buildings then show impressive gains in 'negawatts' (see photos, page 521).

With insulation like that, the building can get its heating from the solar gains through glazing as well as through waste heat from appliances and even our bodies.

Another key technique for temperature control in passive houses is at first counterintuitive: simply let fresh air in from the outside. A pump draws fresh air through a grid of pipes buried several metres underground, where the temperature is relatively constant throughout the year, $10-14{ }^{\circ} \mathrm{C}$ in the United Kingdom, for example. When this fresh air arrives at the house, its temperature has already been modulated - warmed up or cooled down by the ground, depending on the season. Then, in a second trick for heating, the incoming fresh air is put through a heat exchanger to recover $80 \%$ of the heat from the warmer stale air being expelled from the building. This system of air-based cooling and ventilation not only saves energy by recycling heat, but vastly improves air quality.

Many of these same tricks can be used for office buildings and other large structures. However, these buildings tend to be more complex than residential houses, with many more interactions between different interior zones and higher heat loads from staff and machinery. So it is considerably more difficult to make them completely passive. Then, too, research in this area is relatively recent, even in Germany.

Still, EnOB recently published results from 
the construction of 25 prototype passive office and other large buildings, and found that most kept energy for heating, lighting and cooling below $100 \mathrm{kWh} / \mathrm{m}^{2} /$ year. "That's a factor of four smaller than existing equivalent buildings in Germany, and of six than in the United States," says Wagner. Three of the buildings reached energy consumptions of less than $50 \mathrm{kWh} / \mathrm{m}^{2} /$ year.

The EnOB study tested multiple concepts, including passive cooling. One such concept is night ventilation, which is increasingly being deployed in large buildings worldwide. The idea is to open automatically the skylights during the night, when the air in the building is warmer than the outside air. A natural breeze will then release the hot air out the top while drawing in cooler outside air from ventilation grills in the facade.

\section{Cool control}

Another concept tested in the study was to circulate water in boreholes drilled up to 100 metres down, and then pass the water in closed circuits through concrete slabs in the ceilings of the building. The water was a relatively warm $17^{\circ} \mathrm{C}$. But there was so much of it that the cooling effect was comparable to that achieved by air-conditioning compressors. "We use the environment, the ground, as a heat sink," says Wagner.

Many new German houses now use such slab cooling, or 'thermally activated building systems', which were pioneered in Switzerland. The buildings require only very small amounts of energy; all they need is a small pump. A multimillion-euro renovation of the United Nations offices in Geneva, Switzerland, will use a similar system, drawing water from Lake Geneva.

These systems will work in even the hottest areas of California, Wagner maintains, although a small amount of conventional air conditioning might have to kick in during the late afternoon to keep temperatures below what people have become accustomed to. "But it would reduce most of the current needs for air conditioning."

One problem is that the range of daytime temperatures achieved by passive cooling and ventilation are still less predictable than what conventional systems can deliver, in particular in large buildings; careful modelling and scaling are required to cover the possible extremes. As a result, risk-averse architects and engineers worried about potentially unhappy clients tend to stick with the safest option, and sell buildings that use central heating and air conditioning.

"The need is to build more demonstration passive buildings, to show everyone from carpenters to house purchasers that it is not such a strange thing to build an energy-efficient house," says Wall, "and that not only do these buildings work, but they are actually superior to conventional buildings."

Fully passive designs can be adapted to hotter climates, although much less research has been done for those areas. In some cases, it works out cheaper to use a strategy based on renewable energy. That's the tack being taken by Jeff Christian, head of the Buildings Technology Center at the Oak Ridge National Laboratory in Tennessee, to design cheap, energy-efficient homes for low-income families.

In Tennessee, he has to deal with not only heat, but also with high humidity. Underground passive ventilation systems bring in too much moisture for such environments. And although there are possible solutions, such as solar-driven dessication, this is currently too expensive.

Nonetheless, says Christian, low-energy buildings for the mass market are already doable there. His focus is what he describes as "a little bit of solar, and a lot of energy efficiency" - that is, using better insulation and using solar panels. His building in Lenoir City, Tennessee (see photo, page 522), also maximizes cooling through natural cross-ventilation. The solar panels cost $\$ 20,000$ upfront, he says, but he cut costs by mass-producing wall panels and other parts of the building.

For all the progress, though, Christian, for one, is convinced that cheap, low-energy houses will take off in the United States only if the government wields both carrot and stick. "The financial incentives we need to drive this are not in place," he says, adding that tougher and compulsory energy requirements on buildings "is the only way we will get industry to do the research and development to get there".

Yes, he says, green buildings can potentially be built as cheaply as their conventional counterparts, if not more so. But those psychological and institutional barriers are still very real. If engineers, architects and builders have to struggle with, for example, unfamiliar green-architecture techniques, they will incur a heavy 'transaction cost' in the form of confusion, mistakes and delay. And if they have to add renewable energy, they will saddle the project with higher capital construction costs - which clients in the large rental sector will have little interest in paying, as it is the tenants who will reap the rewards in the form of lower energy bills.

The mass-production of wall panels and other parts of the building advocated by Christian is also seen as a promising avenue in Europe. Cost can be reduced further by avoiding one-off designs and constructing an identical series of buildings. "The passive terrace houses we have here in Wuppertal are identical to those in [the German cities of] Wiesbaden or Hannover," says Voss. "The only difference is the colour."

Nonetheless, it is still an open question how quickly passive architecture strategies, combined with renewable energy sources, will become the mainstream of construction. The good news is that the interest is there. Witness the turnout of 30,000 delegates in Chicago last November at the "Greenbuild" conference - which was opened by former US president Bill Clinton. On the last day of the conference, Maria Atkinson, head of sustainability at Lend Lease, a multinational real-estate company, threw out a challenge that should please Voss. "The hotels of Boston have 12 months to step up to the challenge of ensuring they are green for Greenbuild 2008, because this year's delegates will be demanding green hotels as part of their commitment to green buildings." Declan Butler is a senior reporter at Nature, based in France.

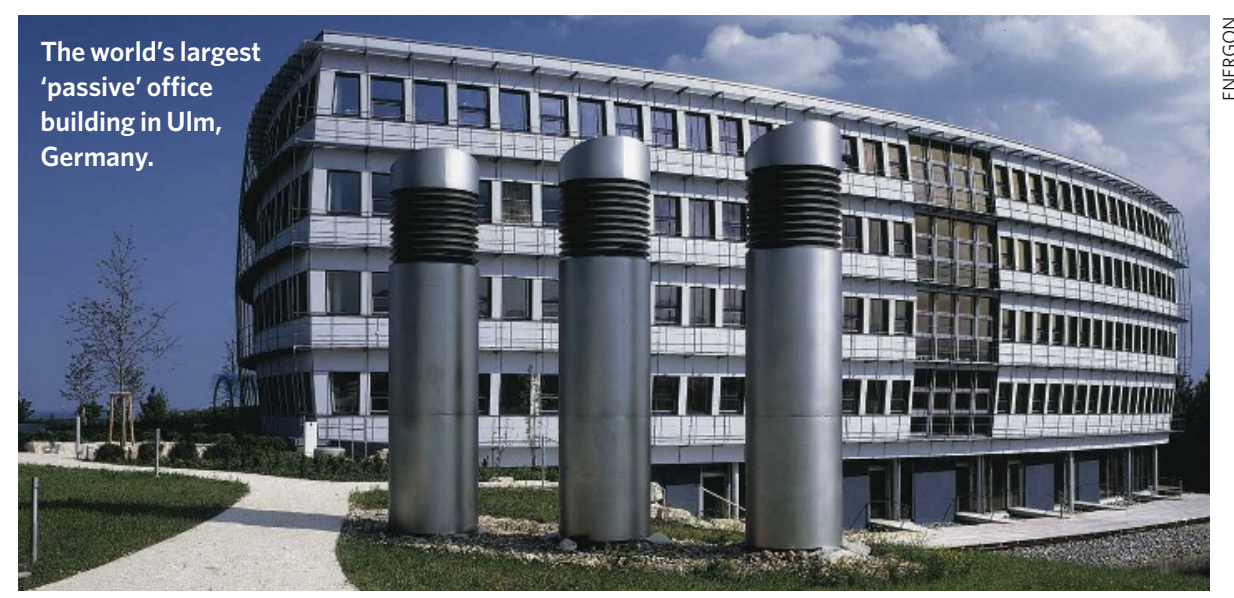

